\title{
Effects of Adult Children's Divorce on Parental Well-being, and Intergenerational Relationships: An Exploratory Study among Korean Families
}

\begin{abstract}
Although the prevalence of divorce in South Korea has greatly increased since late 1990s, the impact of divorce on the parents of adult children in Korean families has received very little attention. This is particularly unfortunate because of the emphasis in Korean culture on family cohesion and obligations. To address these issues, we explored in our study the well-being of the parents of divorced adult children as well as intergenerational relationships among the members of Korean families. Total 113 parents participated (39 males and 74 females), age ranged from 46 to 65 . Of the total participants surveyed, $29 \%$ were parents of divorced children $(N=33)$, with the remainder having children in intact marriages $(N=80)$. The measures examined four areas: (1) demographics, (2) parental psychological well-being, (3) intergeneration relationships, and (3) parental perception of their adult child's marital experience. A series of MANOVA and hierarchical regression analyses were conducted. Our findings indicate important differences between parents of divorced children and parents of non-divorced children on overall well-being, interpersonal relationships, and parental perception, which is consistent with previous studies. Parents of divorced children in this study also reported lower level of
\end{abstract}

Corresponding author: Assistant lecturer, Dept of Social Work, Deaduck University, Gajubgkokro 43, Usungku, Deacheon, R.O.Korea (soohyuning@gmail.com)

${ }^{*}$ Associate professor, Dept of Human Ecology, Syracuse University, 426 Ostrom Avenue, Syracuse, NY 13244 (rmoreno@syr.edu)

Key Words: Parental well-being, intergenerational relationships, divorce, Korean families, life satisfaction intergenerational relationships compared to parents of nondivorced children. Parent-grandchild relationships seem to be particularly important for parental well-being. In addition, we found an unexpected association between parents and their relationship with their former children inlaws. More detailed discussion was discussed.

Over the past few decades, soaring divorce rates have had a major impact on families in many contemporary societies, such as North America, Europe, and Asia. This state of affairs has prompted a vast body of research examining the impact of divorce on families. Much of this work has focused on the children of divorced couples, but relatively little has specifically addressed the consequences of divorce on the parents of adult children. This is particularly the case with regard to the consequences of divorce across cultures. As in the United States, the prevalence of divorce in South Korea has greatly increased since late 1990s (Lee, Kim, Choi, Ham, \& Kim, 2002).

Unfortunately, the impact of divorce on the parents of adult children in Korean families has received very little attention. This is particularly unfortunate because of the emphasis of Korean culture on family cohesion and obligations. Since parent-child relationships are the most important relationships individuals have, these relationships are a major contributor to the well-being of both 
generations (Shapiro, 2004). By understanding the features of the parent-child relationships and the particular problems which they face in deteriorating well-being, it may be possible to plan ways to better help these adult children and their parents in the future. In relations to the family system, strengthen of parent-child relationship as a response to the loss of a central relationship due to divorce can be one of compensation as well as a way of improving both parents' and children's well-being. To address these issues, we explored the well-being of parents of divorced adult-children, as well as divorces' potential influence on intergenerational relationships among Korean family members. However, the study in this area is exploratory because little has been done in Korea.

Parents of children who experience divorce may need to confront a number of divorce related challenges (Temlock, 2006). For example, in an effort to provide emotional support for their children, parents may play a more active role in comforting them through their stressful transition period. In addition, parents may give increased instrumental support by providing material resources and contributing to their children's financial well-being (Hamon \& Cobb, 1993; Bachman \& Chase-Lansdale, 2005). Parents may also broaden their role by increasing their responsibilities with respect to their grandchildren. Not only can parents provide assistance such as childcare, they may also provide emotional and communicative support by serving as mediators between grandchildren and their parents (Hamon \& Cobb, 1993; Johnson, 1985; Johnson \& Barer, 1987; Spitze, Logan, Deane, \& Zerger, 1994).

Unfortunately, parents can suffer from their own negative outcomes as a result of their children's divorce. Initially, parents may experience shock and surprise because they may have been unaware of the seriousness of their child's marital problems. This may be coupled with a sense of shame and disappointment, along with feelings of responsibility and guilt (Brown, 1982; Cherlin \& Furstenberg, 1986; Matthews \& Sprey, 1984; Stephen, 1985). Moreover, the additional financial support can lead to emotional distress, as well as their own financial difficulty (Hamon \& Cobb, 1993). Therefore, it may be anticipated that parents of divorced adults may have differences in well-beings and intergenerational relationships that parents of non-divorced adults.

Well-being is defined as a relatively stable attribute that reflects the extent to which people experience positive affect and possesses favorable views about themselves and their lives (Dush \& Amato, 2005). Well-being is generally conceptualized in positive terms and is typically measured by overall life satisfaction, general happiness, affect, positive interpersonal relationships, good health and physical condition (Dush \& Amato, 2005; Fry, 2000; Lawton, 1991; Ryff, 1989).

Since marital and parental relationships are viewed as the basis for social integration (Umberson, 1992), disruptions in these relationships can create stress that may lead to a decrease in an individual's overall well-being and life satisfaction. This decrease may be short-term or permanent (Lucas, 2007; Lucas, Clark, Georgellis, \& Diener, 2003). In addition, it has been found that divorced individuals have reported the lowest level of life satisfaction when compared to married and unmarried individuals (Argyle, 1999). Since divorce is followed by structural and interactional changes in the family system (Hamon \& Cobb, 1993), divorcing individuals are likely to make adjustments that may lead to a deterioration of their parents' psychological well-being.

Parents may also experience negative outcomes more directly. For example, when children fail to attain "normative" adult lifestyles and get divorced or even remain unmarried, parents are more likely to report ambivalent feelings toward their children (Kaufman \& Uhlenberg, 1998; Johnson, 1998; Newman, 1999; Pillemer \& Suitor, 2002). This ambivalence has been found to be associated with intergenerational conflicts, which may have detrimental effects on parent-child relations (Pillemer \& Suitor, 2002). For example, Ryff and colleagues (1994) found that parents whose offspring turned out "worse" than expected, reported lower levels of overall well-being. This diminished sense of wellbeing may be a result of parents' disappointment, and their own sense of personal failure regarding their childrearing (Connidis \& McMullin, 1993; Hamon \& Cobb, 1993). 
Research on intergenerational family relationships has indicated that parents and their children typically maintain intimate relationships throughout their lives (Bengtson, 1996; Gray \& Geron, 1995; Shapiro, 2004; Umberson, 1992). Examples include parents providing instrumental support and maintaining emotional ties with their adult children (Fingerman \& Bermann, 2000; Pillemer \& Suitor, 1991; Pillemer, Suitor, Mueller-Johnson, Sechrist, \& Heidorn, 2006; Umberson, 1992). Positive parent and adult-child relationships help buffer the negative effects of stressful events on elderly parents (Silverstein \& Bengtson, 1991). For example, previous research has suggested that parents who have greater contact with their children are less likely to experience depression and have relatively low levels of alcohol consumption (Umberson, 1992). Similarly, longitudinal research has shown that elderly parents who have greater emotional bonds with their adult children are more likely to live longer, even in the face of major life catastrophes such as divorce or the death of a spouse (Koropeckyj-Cox, 2002; Silverstein \& Bengtson, 1991). Conversely, poor parent-child relationships have been associated with parental loneliness, depression, and lower life satisfaction (Koropeckyj-Cox, 2002; Lowenstein, Katz, \& GurYaish, 2007).

South Korean culture has been greatly influenced by Confucianism (Kim, Park, Kwon, \& Koo, 2005; Yang, 2003; Yoon, 2000). Confucianism emphasizes strong harmonious familial relationships and traditional values such as loyalty, solidarity, filial piety, and communal life among members (Kim, 1995; Kim, 1997; Yang, 2003). Thus, the well-being of the family is given priority over that of the individual (Yang, 2003). According to the traditional value of filial piety, which is still emphasized in South Korea, elderly parents should be provided with protection, care, and financial support (Maehara, \& Takemura, 2007; Sung, 1998). In addition, parents are expected to practice unselfish devotion and sacrifice for their children, regardless of obstacles (Park \& Kim, 2004).

This emphasis on unity and oneness enforces conformity to social norms among Koreans (Yang \& Rosenblatt, 2001). With respect to marriage, the stigma of divorce is still widespread. Despite recent modernization, South Korean society continues to view divorce as a violation of traditional values that brings shame upon the family (Bauer, Rodriguez, Quiroga, \& Flores-Ortiz, 2000; Kim \& Kim, 2002; Yang \& Rosenblatt, 2001). A 2008 national survey in South Korea revealed that over $50 \%$ of adults opposed divorce (Korean Statistical Information Service, 2009). Moreover, older adults viewed divorce more negatively and skeptically compared to their younger counterparts (Korean Statistical Information Service, 2009; Yang \& Rosenblatt, 2001). In addition, due to the strong influence of filial piety, elderly Koreans see their children's divorce as their own failure (Maehara \& Takemura, 2007; Yang \& Rosenblatt, 2001). Consequently, divorce may have a significant negative influence on Korean parents' well-being.

The role of women in South Korean culture may further complicate the relation between divorce and parental well-being. More specifically, Confucianism emphasizes female inferiority, women's submission to men, and one-sided chastity (Yoon, 2000). This emphasis on female subordination may exacerbate the stigmatization of divorced women (Kim \& Kim, 2002). For example, before revisions to the Family Law in 1990, divorced women in South Korea did not have the right to be the head of a family, to claim a share of family property, or to be the legal guardian of their children (Laurel \& Peterson, 1983). Considering the secondary status of women in marital relationships and social stigma placed on divorced women, the divorce of a daughter (as opposed to a son), may bring about more negative emotional reactions and stress in parents (Committee of Korean Women's history, 1992).

Although the negative effects of divorce have been well established, studies examining the relationship between children's divorce and negative outcomes for parents in South Korea are virtually non-existent. The purpose of this study is to explore the relation between parental well-being and their children's divorce among Korean families. More specifically, the present study addresses the following hypotheses: H1) There are some differences in parental well-being, parents' perceptions of their 
children's (past) marital experience, as well as interpersonal relationships between parents of divorced children and parents of non-divorced child. H2) Divorce has unique impact on the association between intergenerational relationships and parental well-being.

\section{METHOD \\ Participants}

The total number of participants consisted of 113 adults (39 males, 74 females) aged 46 to $65(\mathrm{M}=$ $63.53, \mathrm{SD}=10.13$ ) who have at least one adult child. Eighty percent of the participants were married and living with their spouse, five percent were divorced, and 13 percent reported being a widow or widower. Most participants lived in Pohang, a Korean city, with one of their children residing in the same household. For majority of the participants, monthly income (66.3\%) was less than $2,000(\$ 2,000)$. Of the total participants surveyed, $29 \%$ were parents of divorced children $(N=33)$, with the remainder having children in intact marriages $(N=80)$. The results were presented in Table 1.

\section{Procedures}

The participants were recruited through five community churches and three senior citizen centers in Pohang, South Korea. Letters explaining the purpose of the study and informed consent forms were sent to church leaders. Senior center representatives were asked for their assistance in recruiting parents for the study. Participants had to have at least one child aged 20 or older to be included in the study.

\section{Measurement}

The measures examined four areas: (1) demographics, (2) parental psychological well-being, (3) intergeneration relationships, and (3) parental perception of their adult child's marital experience. Because these instruments were not available in Korean, the first author and a professional translator translated all instruments into Korean and then back into English to increase the accuracy of translation.
Table 1. Demographic Information about Participants $(N=113)$

\begin{tabular}{lcc}
\hline $\begin{array}{c}\text { Variables about participants } \\
\text { (Parent) }\end{array}$ & Frequency & Percentage (\%) \\
\hline Gender & 39 & 34.5 \\
Male & 74 & 65.5 \\
Female & & \\
Education & 16 & 14.2 \\
Completed graduate program & 30 & 26.5 \\
Completed collage program & 31 & 27.4 \\
Completed high school & 9 & 7.9 \\
Completed middle school & 27 & 23.8 \\
Others & & \\
Income/month & 15 & 13.3 \\
More than $\$ 4,000$ & 10 & 8.8 \\
\$3,000-4,000 & 10 & 8.8 \\
\$2,000-3,000 & 24 & 21.2 \\
\$1,000-2,000 & 51 & 45.1 \\
Less than \$1,000 & & \\
Marital status & 91 & 80.5 \\
Married & 6 & 5.3 \\
Divorced & 15 & 13.3 \\
Widowed & 1 & 0.9 \\
Others & & \\
\hline
\end{tabular}

Demographics Participants were asked to provide information about their age, level of education, occupation, income, and marital status.

Parental well-being The parental psychological well-being was assessed along two dimensions: overall life satisfaction and psychiatric symptoms.

The Satisfaction with Life Scale (SWLS) was used to assess participants' overall life satisfaction (Diener, Emmons, Larsen, \& Griffin, 1985). The SWLS consists of five items inquiring about individuals' judgment of their quality of life, for example, "In most ways, my life is close to my ideal." Each item was scored using a Likert scale (1=strongly disagree, $2=$ disagree, $3=$ neither agree nor disagree, $4=$ agree, $5=$ strongly agree). Item scores were summed to obtain a total score. High scores indicated more satisfaction. The instrument appears to have excellent test-retest reliability, with a correlation of 0.82 . In 
this study, internal reliability of the scale was $\alpha=0.91$.

The Symptoms Checklist (SC) was used to assess participants' level of psychiatric symptoms (Bartone, Ursano, Wright, \& Ingraham, 1989). The SC measures four dimensions of psychopathology including depression/withdrawal, hyper-alertness, generalized anxiety, and somatic complaints, for example, "Hands sweat, feel damp, and clammy," and "Taking medication to sleep or calm down." Each item was scored using a Likert scale $(1=$ none, $2=\mathrm{a}$ little, $3=$ often, $4=$ very often). Item responses of total 20 items were summed for a total score of psychiatric symptoms, with higher scores reflecting more symptoms. In this study, internal reliability of the scale was $\mathrm{a}=0.89$.

Parents' perceptions about their child's (past) marital experience A measure of parents' perceptions about their child's (past) marital experience was developed to assess perceived parental satisfaction with their children's current or past marital lives. The two-item measure asked, a) "Are (Were) you happy about your son/daughter's (past) marriage?" and b) "Do you think your son/daughter is (was) happy about her/ his (past) marriage?" Each item was scored using a Likert scale from $1=$ not at all to $5=$ absolutely true. Factor analysis was conducted and items were loaded between .88 and .87 . Item scores were summed for a total score, with higher scores indicating more positive perception. Internal reliability of these items was $\alpha=.87$.

Intergenerational relationships The following intergenerational relationships were measured: parentadult child, parent-grandchildren, and parent- (ex) child-in-law. The Quality of Relationships Inventory (Pierce, Sarason, \& Sarason, 1991) was used to assess the relationships between parents and their adult children. This inventory is a structured survey that assesses three specific dimensions of relationships: (1) social support, for example, "To what extent could you turn to your child for advice about problems?," (2) perceptions of relationships as positive, important, and secure, for example, "How positive a role does your child play in your life?", and (3) conflict and ambivalence resulting from the relationship, for example, "How often do you need to work hard to avoid conflict with your child?" Each item was scored using a Likert scale ( $1=$ not at all, $2=\mathrm{a}$ little, $3=$ quite a bit, $4=$ very much) and responses were summed for a total score of parent-adult child relationship quality with higher scores reflecting better relationships. Principal component analysis revealed that five out of 25 items associated with social support dimension had low factor loadings, which were under .30; therefore, these five items eliminated and 20 items were used for this study. Internal reliability of the scale in this study was a = 0.85 . In order to establishing structural equivalence, a series of factor analysis was conducted and three items were determined using principal component analysis among five: loadings were between .75 to 89.

Relationships with their grandchildren were measured with three items, which were developed by investigators for the purpose of study, such as a) "Are you happy with your relationship with your grandchildren?" b) "Are you emotionally close to your grandchildren?" and c) "Are you meeting your grandchildren often?" Item scores were summed for a total score, with higher scores indicating more positive relationships. Internal reliability of the scale of the parent-grandchildren was $\alpha=.69$. One item was used to assess relationships with (ex) child-inlaw; "Are you emotionally close to your (ex) son/ daughter-in-law?" Respondents indicated the degree of their relationships using a 5-point Likert scale from $1=$ not at all to $5=$ absolutely yes.

\section{RESULTS}

The data was first examined for missing data and inaccuracy. The amount of missing data was small (less than 1\%), hence the missing data were substituted with the mean values. The data set was also assessed for any outliers by examining univariate frequency distributions and bivariate scatter plots. Normality was tested using Skewness and Kurtosis statistics and homogeneity of variance of all key variables was tested using the Levene's statistic. As suggested by Brown (1997), the range of 
standard errors of skewness and kurtosis of the variables in this study were within the expected range of chance fluctuation.

A series of preliminary analyses were conducted to explore the associations among various demographic and outcome variables. The analyses showed some significant correlations among demographic variables and major variables. Parental income was positively related to life satisfaction ( $r=$ $.3, p<.01)$ and negatively to psychiatric symptoms $(r=-.34, p<.01)$. On the contrary, parents' marital status was negatively related to life satisfaction $(r=$ $-.26, p<.01)$ and positively to psychiatric symptoms $(r=.38, p<.01)$. Parents' gender was negatively related to life satisfaction $(r=-.19, p<.05)$. Parents' age was positively related to psychiatric symptoms $(r=.24, p<$ $.05)$ and negatively related to relationship with grandchildren $(r=-.26, p<.01)$.

These preliminary analyses suggest that parents with higher levels of life satisfaction were more likely to be married, male, and have higher incomes. Similarly, parents with lower levels of psychiatric symptoms were also more likely to be male and have higher income, but also married and younger. In addition, younger parents were more likely to report better relationships with their children. These significant demographic variables (parents' age, income, and marital status) were controlled throughout a series of major analysis. The results were presented in Table 2.

Next, a one-way multivariate analysis of variance (MANOVA) was conducted to assess any differences between parents of divorced children and parents of non-divorced children on parental well-being (life satisfaction, psychiatric symptoms), with parental age, income, and marital status as covariates. The multivariate analysis indicated a significant main effect for parental well-being, $F(3,109)=3.03, p=.05$. Subsequent univariate analyses revealed a significant difference between groups on psychiatric symptoms $(F(1,111)=5.61, p=.02)$, indicating that parents of divorced children $(M=1.82, S D=.47)$ reported higher level of psychiatric symptoms compared to parents of non-divorced children $(M=1.64, S D=.44)$.

A second MANOVA was conducted to assess any differences between parents of divorced children and parents of non-divorced children on intergenerational relationships (with adult child, grandchild, and child-in-law respectively) with parental age, income, and marital status as covariates. The analysis indicated a significant main effect for total intergenerational relationships, $F(3,109)=24.31, p=.00$. Subsequent univariate analyses revealed a significant difference between groups on intergenerational relationship in

Table 2. Correlations

\begin{tabular}{|c|c|c|c|c|c|c|c|c|c|c|c|}
\hline & 1 & 2 & 3 & 4 & 5 & 6 & 7 & 8 & 9 & 10 & 11 \\
\hline Gender & 1 & & & & & & & & & & \\
\hline Income & $-.44^{*}$ & 1 & & & & & & & & & \\
\hline Marital status & $.20^{*}$ & $-.30 * *$ & 1 & & & & & & & & \\
\hline Education & -.00 & .12 & -.02 & 1 & & & & & & & \\
\hline Occupation & $.44^{* *}$ & $-.62 * *$ & .07 & -.16 & 1 & & & & & & \\
\hline Age & -.12 & $-.33 *$ & .04 & .08 & $.22 *$ & 1 & & & & & \\
\hline LS & $-.19^{*}$ & $.30^{* *}$ & $-.26^{* *}$ & -.01 & -.17 & -.17 & 1 & & & & \\
\hline PS & .16 & $-.34 * *$ & $.38^{* *}$ & -.03 & .16 & $.24 *$ & $-.41 * *$ & 1 & & & \\
\hline RAC & .05 & .04 & -.15 & -.03 & -.09 & -.13 & $.22 *$ & $-.22 *$ & 1 & & \\
\hline $\mathrm{RCL}$ & -.01 & .11 & -.10 & .14 & -.08 & -.12 & -.08 & -.11 & $.34^{* *}$ & 1 & \\
\hline RGC & -.01 & .08 & -.12 & -.11 & -.05 & $-.26^{* *}$ & $.21^{*}$ & $-.32 * *$ & $.56^{* *}$ & $.34^{* *}$ & 1 \\
\hline PP & -.05 & .18 & -.16 & .17 & -.10 & -.17 & .04 & $-.19^{*}$ & $.32^{* *}$ & $.86^{* *}$ & $.39 * *$ \\
\hline
\end{tabular}

Note: LS=Life satisfaction, PS=Psychiatric Symptoms, RAC=Relationship with adult-child, RCL=Relationship with child-in-law, RGC=Relationship with grandchildren, $\mathrm{PP}=$ Parental perception about adult-child's (past) marital experience ${ }^{*} \mathrm{p}<.05,{ }^{*} * \mathrm{P}<.01$. 
Table 3. Multivariate analysis of variance for parental well-being on child's marital status $(N=113)$

\begin{tabular}{lccc}
\hline \multicolumn{1}{c}{ Variables } & Divorced Group M (SD) & Married Group M (SD) & F (df) \\
\hline Life Satisfaction & $3.14(.82)$ & $3.08(.93)$ & $.11(1,111)$ \\
Psychiatric Symptoms & $1.83(.47)$ & $1.64(.44)$ & $4.33(1,111)^{*}$ \\
\hline
\end{tabular}

Note. ${ }^{*} p<.05, * * p<.01$; Multivariate $F(3,109)=3.03, p=0.05$, Wilks' Lambda $=.95, \eta^{2}=.05$

Table 4. Multivariate analysis of variance intergenerational relationships on adult child's marital status $(N=113)$

\begin{tabular}{lccc}
\hline \multicolumn{1}{c}{ Variables } & Divorced Group M (SD) & Married Group M (SD) & $\mathrm{F}(\mathrm{df})$ \\
\hline Relationships with adult child & $2.56(.37)$ & $2.71(.31)$ & $6.53(1,111)^{*}$ \\
Relationships with grandchildren & $3.56(.98)$ & $3.91(.81)$ & $4.57(1,111)^{*}$ \\
Relationships with child in-law & $2.18(1.01)$ & $3.80(.87)$ & $72.46(1,111)^{* *}$ \\
\hline
\end{tabular}

Note. ${ }^{*} p<.05,{ }^{*} p<.01$; Multivariate $F(3,109)=24.31, p=0.000$, Wilks' Lambda $=.59, \eta^{2}=.40$

Table 5. Summary of Hierarchical Multiple Regression Analysis $(N=113)$

\begin{tabular}{|c|c|c|c|c|c|c|c|c|c|}
\hline & \multicolumn{3}{|c|}{ Relationship with Adult-child } & \multicolumn{3}{|c|}{ Relationship with Grandchildren } & \multicolumn{3}{|c|}{ Relationship with (Ex) Child-in-law } \\
\hline & STEP 1 & STEP 2 & STEP 3 & STEP 1 & STEP 2 & STEP 3 & STEP 1 & STEP 2 & STEP 3 \\
\hline \multicolumn{10}{|l|}{ BETA } \\
\hline Age & -.08 & -.08 & -.09 & -.08 & -.04 & -.04 & -.08 & -.10 & -.14 \\
\hline Income & $.25^{*}$ & $.27 *$ & $.28^{*}$ & $.25^{* *}$ & $.27^{* *}$ & $.25^{* *}$ & $.25^{* *}$ & $.26^{* *}$ & $.27^{* *}$ \\
\hline MS & $-.18^{*}$ & -.17 & -.17 & $-.18^{*}$ & -.17 & -.19 & $-.18^{*}$ & $-.20^{*}$ & -.15 \\
\hline DV & & -.15 & -.14 & & -.13 & -.12 & & -.19 & .09 \\
\hline IR & & $.21^{*}$ & .26 & & $.20^{*}$ & $.22 *$ & & .10 & .11 \\
\hline IR $x$ DV & & & .14 & & & .12 & & & $-.38 * *$ \\
\hline$R^{2}$ & .11 & .15 & .16 & .12 & .17 & .19 & .11 & .11 & .17 \\
\hline$\Delta R^{2}$ & $.12 *$ & $.05^{*}$ & .02 & $.12^{* *}$ & $.05^{*}$ & .01 & $.12 * *$ & .11 & $.07 * *$ \\
\hline$\Delta F$ & $7.62^{* *}$ & $3.54 * *$ & $2.25^{* *}$ & $7.62^{* *}$ & $3.30^{* *}$ & $1.74 * *$ & 7.62 & $1.05^{* *}$ & $9.44 * *$ \\
\hline $\mathrm{df}$ & 2,110 & 1,108 & 1,107 & 2,110 & 1,108 & 1,107 & 2,110 & 1,108 & 1,107 \\
\hline
\end{tabular}

Note: Dependent variable=Life Satisfaction. MS=Marital Status, DV=Divorce, IR=Intergenerational Relationships. ${ }^{*} \mathrm{p}<.05,{ }^{* *} \mathrm{P}<.01$.

all categories, relationships with adult child, $F(1$, $111)=5.01, p=.02$, (ex) child-in-law, $F(1,111)=73.0$, $p=.00$, and grandchildren, $F(1,111)=3.76, p=.05$. Parents of non-divorced children $(M=2.56, S D=.37$; $M=3.56, S D=.98 ; M=2.18, S D=1.01$ respectively) reported more positive relationships with their adult child, grandchildren, and in-law compared to their counterparts $(M=2.71, S D=.31 ; M=3.91, S D=.81 ; M=$ $3.80, S D=.87$ respectively).

An independent-sample t-test was conducted between adult-child's (past) marital experience (divorced, non-divorced) on parental perception of adult-child's (past) marital experience. The analysis indicated a significant differences between groups, $t$ $(111)=-8.69, p=.00$. The analysis indicates that parents of divorced children reported more negative perception about their child's marriage $(M=2.11$, $S D=1.06)$ than parents of non-divorced children $(M=3.92, S D=.86)$.

Finally, to further investigate the correlates of parental well-being (life satisfaction, psychiatric symptoms) three hierarchical multiple regressions were conducted. Three covariates (parental age, income, marital status) were entered in the first step. Intergenerational relationships and divorce variables were entered into the second step and the interaction 
between of intergenerational relationships and divorce were entered into the last step. Table 3 and 4 summarize the results of the hierarchical regression analyses.

Step 1 of the intergenerational relationship model showed that parental income was a significant predictor of psychiatric symptoms $(\beta=.25, p<.01)$ and life satisfaction $(\beta=.25, p<.01)$. Also, parental marital status was a significant predictor of life satisfaction $(\beta=.18, p<.05)$. Relationship with adultchild and grandchildren in step 2 were significant predictors of life satisfaction $(\beta=.21, p<.05 ; \beta=.20, p<$ .05 respectively) and psychiatric symptoms $(\beta=.16, p$ $<.05 ; \beta=.20, \quad p<.05$ respectively). A significant predictive function of the interaction between relationships with Grandchildren and divorce was showed in psychiatric symptoms $(\beta=-.09, p<.05)$ and life satisfaction $(\beta=-.38, p<.01)$ adding $7 \%$ to the explained variance.

\section{DISCUSSION}

This study explored the effects of adult children's divorce on their parents' well-being, intergenerational relationships (children, in-laws, and grandchildren), and parental perceptions of their child's marital experience in Korean families. The findings indicate important differences between the parents of divorced children and the parents of non-divorced children on both overall well-being and interpersonal relationships. We found that parents of divorced children reported more psychiatric symptoms (such as depression, anxiety, and physical illness) compared to parents of non-divorced children.

The findings regarding the effects of children's divorce on parental well-being are consistent with previous studies conducted in the United States, which found that parents of divorced children reported increased disappointment, shame, sadness, and direct feelings of ambivalence after their child's divorce (Pillemer \& Suitor, 2002). Moreover, these parents reported lower levels of well-being and an increase in mental health symptoms, such as depression, anxiety, and physical illness (Kaufman \& Uhlenberg, 1998; Johnson, 1998; Newman, 1999;
Pillemer \& Suitor, 2002). Despite Korea’s modernization and cultural change, its value system continues to emphasize family responsibility, loyalty, and obligation (Maehara \& Takemura, 2007; Kim, 1997). Korean parents seem to form a close psychological connection with their offspring and have high expectations for them to succeed. Divorce may carry a stigma for divorced children as well as for parents. Parents may perceived themselves as failing to raise children that follow a "normal" marital and familial trajectory; in addition, this may contribute to feelings of depression and anxiety.

Parents of divorced children in this study reported lower level of intergenerational relationships compared to parents of non-divorced children. European researchers also examined social consequence of divorce and found relational difficulties between parents and their divorced children as contacts with friends, families, and relatives declined significantly after divorce (Kaltthijs \& Uunk, 2007). Feelings of disappointment and/or embossment may be developed that can result in emotional distance between parents and their adult children if parents see an adult child's divorce as failure.

The association between intergenerational relationships and parental well-being is quite interesting; in addition, the findings suggest that parent-grandchild relationships are particularly important. When parents have a good relationship with their grandchildren, their life satisfaction tends to be higher and mental health symptoms are less severe for divorced and non-divorced groups, even when taking into account the parents' relationship with their adult-child. This is consistent with other studies that have shown that grandparents and grandchildren who interact with each other often tend to be emotionally close and have mutually satisfying relationships (Smith \& Drew, 2002).

Researchers have found that elderly parents experience a steeper increase in depressive symptoms when they lose contact with grandchildren due to an adult child's divorce or separation (Drew \& Silverstein, 2007). Others have reported that grandparents experience negative emotional and physical symptoms, such as intense grief, symptoms 
of posttraumatic stress disorder, mental health problems, lower life satisfaction, and depression when they experience a loss of contact with their grandchildren (Drew \& Smith, 1999; Kruk, 1995). Thus, a loss of contact with grandchildren due to an adult child's divorce could be emotionally devastating, particularly given the lack of control that parents possess in remedying the situation.

We also found an unexpected association between parents and their relationship with their former son in-laws or daughter in-laws. We found an inverse relationship between the level of life satisfaction and mental-health symptoms for parents of divorced children and the relationship with their former son in-law or daughter in-law. When divorce effect was entered, parents who had poor relations with their child's ex-spouse experienced greater parental well-being. Initially, we found this counter intuitive because intergenerational relationships and parental well-being are generally positively associated. However, divorce is typically associated with high levels of interpersonal conflicts and an accumulation of stress factors such as economic difficulties, social stigma, and feelings of personal failure (Wallerstein \& Blakeslee, 1989). Due to these negative experiences and emotional distress, divorce often represents an escape from a stressful situation for the couple involved. The parents of divorced children may experience a similar relief and may be "happy" that the relationship ended. They may maintain "bad feelings" for their former in-law, blaming them for their child's bad marriage.

The familial relationships among Koreans might be understood in the context of Confucianism. A central theme of Confucianism concerns social relationships (Yoon, 2000). Children owe strong duties of reverence and service to their parents. In turn, parents have duties of benevolence and concern towards juniors and children. Although the role of Confucianism is less evident in contemporary Korean families, extensive filial duties toward elders and great care towards their children are still practiced in Korean's daily lives (Park, 1994). Considering the strong emphasis on familial relationships and social harmony among Korean families (Kim, 1995), life events that threaten this harmony may bring distress and depressive symptoms for the elderly (Leong, Tseng, \& Wu, 1985).

Collectively, our findings are consistent with those of researchers in other countries. Among Koreans, the negative effects of divorce are far reaching. Adult children's divorce can negatively influence their parents' well-being and family relationships. We should be cautious, however, in generalizing our findings. The sample is not representative because the data were collected from one specific region. Since the nature of this study is exploratory, it is hard to actually compare the findings of this study with results of some previous studies. This is especially true for association with relationships with parents. Considering the uniqueness of Korean culture, the results of this study may differ according to the cultural context. Continued investigation is needed to contextualize the research findings, since the divorced population is increasing. Given the size of the sample, it may not be appropriate to extend the findings from the present study to other populations and circumstances; therefore, larger samples from diverse settings are suggested for future research.

Another limitation of the survey methodology is that surveys rely on self-reported data and may introduce a measurement error into the data (Singleton \& Straights, 1999). In some cases, respondents may report inaccurate information because of poor memory or a misunderstanding of the survey questions. In other cases, respondents may intentionally give false responses because of a desire to be viewed positively by an unknown investigator or because of fear related to reporting sensitive information. This study relied on divorcee's parents, which can be considered a sensitive topic in some families; therefore, intentional inaccurate answers may be a factor in the measurement errors. The inclusion of multiple informants is desirable; in addition, the inclusion of qualitative information, based on in-depth interviews, contributes to the picture of the well-being of parents of divorcees.

Additional measures such as the amount of time that has elapsed since the divorce might provide important insight into the parents' psychological adjustment, since time has been an important factor 
in the psychological adjustment of divorcees and their children (Munoz-Eguileta, 2007; Stone, 2001; Ladd \& Zvonkovic, 1995). The questions about the time of divorce were asked; however, only few of participants answered. Religion/spiritualty should be included because it may be an important aspect of Korean life; however, it was not included in this study although participants were recruited from local churches.

Family size can be included. For example, if an only child got divorced, it may be suspected that the pressure is greater on the marriage and marital outcome of the one child and the parents' investment in the marriage of this child. In addition, the use of in-depth interviews regarding the nature of parentchild relationships and divorce experiences in Korean society might distinguish important cultural nuances in this type of marital transition among various family members.

\section{REFERENCES}

Argyle, M. (1999). Causes and correlates of happiness. In Kahneman, D., Diener, E. and Schwarz N. (Eds.), Foundations of Hedonic Psychology: Scientific Perspectives on Enjoyment and Suffering. New York: Russell Sage Foundation.

Bachman, H. J., \& Chase-Lansdale, P. L. (2005). Custodial grandmothers' physical, mental, and economic well-being: Comparisons of primary caregivers from low-income neighborhoods. Family Relations, 54, 475-487.

Bartone, P. T., Ursano, R. J., Wright, K. M., \& Ingraham, L. H. (1989). The impact of a military disaster on the health of assistance workers: A prospective study. Journal of Nervous and Mental Disease. 177, 317-328.

Bauer, H. M., Rodriguez, M. A., Quiroga, S. S., \& Flores-Ortiz, Y. (2000). Barriers to health care for abused Latino and Asian immigrant women. Journal of Health Care for the Poor and Underserved, 11, 33-45.

Bengtson, V. L. (1996). Continuities and discontinui- ties in intergenerational relationships over time. In V.L. Bengtson (Ed.), Adulthood and aging: Research on continuities and discontinuities (pp. 271-303). New York: Springer Publishing.

Bevvino, D. L., \& Sharkin, B. S. (2003). Divorce adjustment as a function of finding meaning and gender differences. Journal of Divorce $\mathcal{E}$ Remarriage, 39, 81-97.

Brown, E. M. (1982). Divorce and the extended family: A consideration of services Journal of Divorce, 5, 159-170.

Brown, J. D. (1997). Skewness and kurtosis. JALT Testing $\mathcal{E}$ Evaluation SIG Newsletter, 1, 20-23.

Cargan, L., \& Whitehurst, R. N. (1990). Adjustment differences in the divorced and the re-divorced. Journal of Divorce \& Remarriage, 14, 49-78.

Cherlin, A. J., \& Furstenberg, F. F. (1986). The new American grandparent. New York: Basic Books.

Committee of Korean Women's history. (1992). History of Korean women (Ed.). Korea: Ewha Women's University Press.

Connidis, I. A., \& McMullin, J. A. (1993). To have or have not: Parental status and the subjective wellbeing of older men and women. The Gerontologist, 33, 630-636.

Diener, E., Emmons, R. A., Larsen, R. J., \& Griffin, S. (1985). The Satisfaction with Life Scale. Journal of Personality Assessment, 49, 1-5.

Drew, L. M., \& Silverstein, M. (2007). Grandparents' psychological well-being after loss of contact with their grandchildren. Journal of Family Psychology, 21, 372-379.

Drew, L. A., \& Smith, P. K. (1999). The impact of parental separation/divorce on grandparent-grandchild relationships. International Journal of Aging and Human Development, 48, 191-216.

Dush, C. M., \& Amato, P. R. (2005). Consequences of relationship status and quality for subjective wellbeing. Journal of Social and Personal Relationships, 22, 607-627.

Fingerman, K. L. \& Bermann, E. (2000). Applications of family systems theory to the study of adulthood. International Journal of Aging \& Human Devel- 
opment, 51, 5-29.

Fry, P. S. (2000). Religious involvement, spirituality and personal meaning for life: Existential predictors of psychological well-being in community-residing and institutional care elders. Aging $\mathcal{E}$ Mental Health, 4, 375-387.

Gray, C. A., \& Geron, S. M. (1995). The other sorrow of divorce: The effects on grandparents when their adult children divorce. Journal of Gerontological Social Work, 23, 139-159.

Hamon, R. R., \& Cobb, L. L. (1993). Parents' experience of and adjustment to their adult children's divorce: Applying family stress theory. Journal of Divorce \& Remarriage, 21, 73-94.

Horwitz, A. V., White, H. R., \& Howell-White, S. (1996). The use of multiple outcomes in stress research: A case study of gender differences in responses to marital dissolution. Journal of Health and Social Behavior, 37, 278-291.

Johnson, C. L. (1985). Grand-parenting opinions in divorcing families: An anthropological perspective. In V.L. Bengstron \& J.F. Robertson (Eds.). Grandparenthood (pp. 81-96). Beverly Hills, CA: Sage.

Johnson, C. L. (1998). Effects of adult children's divorce on grandparenthood. In M.E. Szinovacz (Ed.), Handbook on grandparenthood. (pp. 184-199). Westport, CT: Greewood Press/Greenwood Publishing Group.

Johnson, C. L., \& Barer, B. (1987). Marital instability and the changing kinship networks of grandparents. The Gerontologist, 27, 330-335.

Kaltthijs, M., \& Uunk, W. (2007). Regional value differences in Europe and the social consequences of divorce: A test of the stigmatization hypothesis. Social Science Research, 36, 447-468.

Kaufman, G., \& Uhlenberg, P. (1998). Effects of life course transitions on the quality of relationships between adult children and their parents. Journal of Marriage $\mathcal{E}$ the Family, 60, 924-938.

Kim, H. R. (1995). Men's marriage and women's divorce. Seoul, Korea: Alternative Culture.

Kim, U. (1997). Asian perspectives on psychology. In H.S.R. Kao \& D. Sinha (Eds.), Asian perspectives on psychology. London: Sage.

Kim, M. H. (1995). Gender, class, and family in lateindustrializing South Korea. Asian Journal of Women's studies, 1, 58-86.

Kim, J. Y., \& Kim, H. (2002). Stigma in divorces and its deterrence effect. Journal of Socio-Economics, 31, 31-44.

Kim, C. -A., Park, Y. -S., Kwon, Y. -E., \& Koo, J. (2005). Value of children, parent-child relationship, and social change in Korea: Indigenous, cultural, and psychological analysis. Applied Psychology: An International Review, 54, 338-354.

Korean Statistical Information Service. (2009). Opinions about divorce in 2008. Retrieved from http://www. kosis.kr

Koropeckyj-Cox, T. (2002). Beyond parental status: Psychological well-being in middle and old age. Journal of Marriage and Family, 64, 957-971.

Kruk, E. (1995). Grandparent-grandchild contact loss: Findings from a study of A Grandparents Rights' members. Canadian Journal on Aging, 14, 737-754.

Ladd, L. D., \& Zvonkovic, A. (1995). Single mothers with custody following divorce. Marriage \& Family Review, 20, 189-211.

Laurel, K., \& Peterson, M. (1983). Korean women: View from the inner room. New Haven: East Rock Press.

Lawton, M. P. (1991). A multidimensional view of quality of life in frail elders. In R. P. Abeles (Ed.), The concept and management of quality of life in the frail elderly. NY: Academic Press.

Lee, D. -W., Kim, H. -J., Choi, S. -H., Ham, I. -H., \& Kim, S. -Y. (2002). Current address of Korean families. Seoul, Korea: Hak-Jy Sa.

Leong, F. T. L., Tseng, W. S., \& Wu, D. Y. H. (1985). Cross-cultural variations in stressful life events: A preliminary study. American Mental Health Counselors Association Journal. 7, 72-77.

Lowenstein, A., Katz, R., \& Gur-Yaish, N. (2007). Reciprocity in Parent-Child Exchange and Life Satisfaction among the Elderly: A Cross-National Perspective. Journal of Social Issues, 63, 865-883.

Lucas, R. E. (2007). Adaptation and the set-point 
model of subjective well-being: Does happiness change after major life events? Current Directions in Psychological Science, 16, 75-79.

Lucas, R. E., Clark, A. E., Georgellis, Y., \& Diener, E. (2003). Re-examining adaptation and the set point model of happiness: Reactions to changes in marital status. Journal of Personality and Social Psychology, 84, 527-539.

Maehara, T., \& Takemura, A. (2007). The norms of filial piety and grandmother roles as perceived by grandmothers and their grandchildren in Japan and South Korea. International Journal of Behavioral Development, 31, 1159-1185.

Matthews, S. H., \& Sprey, J. (1984). The impact of divorce on grandparenthood: An exploratory study. The Gerontologist, 24, 41-47.

Munoz-Eguileta, A. (2007). Irrational beliefs as predictors of emotional adjustment after divorce. Journal of Rational-Emotive \& Cognitive-Behavior Therapy, 25, 1-15.

Newman, K. S. (1999). No shame in my game: The working poor in the inner city. New York: Alfred A. Knopf.

Park, L. S., (1994). Confucianism and violence against women. God's Image, 13, 12-19.

Park, Y. S., \& Kim, U. (2004). Parent-child relationship in Korea: Indigenous psychological analysis of self-concept and family role. Seoul, Korea: Kyoyook Kwahaksa.

Pierce, G. R., Sarason, I. G., \& Sarason, B. R. (1991). Quality of relationships inventory: Assessing the interpersonal context of social support. In B. R. Burleson, T. L. Albrecht, \& I. G. Sarason (Eds.), Communication of social support (pp. 247-266). Thousand Oak, CA: Sage.

Pillemer, K., \& Suitor, J. J. (1991). Relationships with children and distress in the elderly. In K. Pillemer \& K. McCartney (Eds.), Parent-child relations throughout life (pp.163-178). Hillsdale, NJ: Lawrence Erlbaum.

Pillemer, K., \& Suitor, J. J. (2002). Explaining mothers' ambivalence toward their adult children. Journal of Marriage $\mathcal{E}$ the Family, 64, 604-613.

Pillemer, K., Suitor, J. J., Mueller-Johnson, K., Sechrist,
J., \& Heidorn, J. (2006). Parent-adult child relations. In R. Schulz (Ed.), Encyclopedia of aging. New York: Macmillan.

Ryff, C. D. (1989). Happiness is everything, or is it? Explorations on the meaning of psychological wellbeing. Journal of Personality and Social Psychology, 57, 1069-1081.

Ryff, C. D., Lee, Y. H., Essex, M. J., \& Schmutte, P. S. (1994). My children and me: Midlife evaluations of grown children and of self. Psychology and Aging, 9, 195-205.

Shapiro, A. (2004). Revisiting the generation cap: exploring the relationships of parent/adult-child dyads. International Journal of Aging and Human Development, 58, 127-146.

Sheets, V. L., \& Braver, S. L. (1996). Gender differences in satisfaction with divorce settlements. Family Relations, 45, 336-342.

Silverstein, M., \& Bengtson, V. L. (1991). Do close parent-child relations reduce the mortality risk of older parents? Journal of Health and Social Behavior, 32, 382-395.

Singleton, R. A., \& Straights, B. C. (1999). Approaches to social research. New York: Oxford University Press. Smith, P. K., \& Drew, L. M. (2002). Grandparenting. In M.Bornstein (Ed.), Handbook of parenting: Vol. 3. Status and social conditions of parenting (2nd ed.), (pp. 141-172). Mahwah, NJ: Erlbaum.

Spitze, G., Logan, J. R., Deane, G., \& Zerger, S. (1994). Adult children's divorce and intergenerational relationships. Journal of Marriage and the Family, 56, 279293.

Stephen, T. (1985). Symbolical interdependence and post-break-up distress: A reformulation of the attachment construct. Journal of Divorce, 8, 1-16.

Stone, G. (2001). Father postdivorce well-being: An exploratory model. Journal of Genetic Psychology, 162, 460-477.

Sung, K. (1998). Filial piety in modern times: Timely adaptation and practice patterns. Australian Journal of Ageing, 17, 88-92.

Temlock, M. (2006). Your child's divorce: What to expect? What you can do. Atascadero, CA: Impact Publishers. 
Umberson, D. (1992). Relationships between adult children and their parents: Psychological consequences for both generations. Journal of Marriage and the Family, 54, 664-674.

Wallerstein, J. S., \& Blakeslee, S. (1989). Second chances: Men, women, and children a decade after divorce. New York: Tickner \& Fields.

Yang, O. K. (2003). Family structure and relations. Social Indicators Research, 62, 121-148.

Yang, S., \& Rosenblatt, P. C. (2001). Shame in Korean families. Journal of Comparative Family Studies, 32, 361-375.

Yoon, J. A. (2000). The challenge of the marriage metaphor of Hosea 1-3 to Confucian marriage practices in Korea. Retrieved from http://eapi.admu.edu.ph/ eapr00/yoon.htm

Received November 7, 2011

Revised February 22, 2012

Accepted March 26, 2012 